\title{
Türkiye'deki Yenidoğan Hekimlerinin Klinik Ultrasonografi Kullanımı ve Bakışının Değerlendirildiği Ulusal Anket Çalışması
}

\section{A National Survey and Assesment for Clinical Ultrasound Use of Neonatal Physicians in Turkey}

\author{
Burak Ceran (0000-0001-5914-5325), Ufuk Çakır (0000-0002-9409-185X), Yavuzalp Solak* (0000-0001-5274-7606), \\ Cüneyt Tayman (0000-0002-9970-0714)
}

Sağlık Bilimleri Üniversitesi, Ankara Bilkent Şehir Hastanesi, Neonatoloji Kliniği, Ankara, Türkiye

*Sağlık Bakanlığı, Dörtyol Illçe Sağlık Müdürlüğü Halk Sağlığı Birimi, Hatay, Türkiye

Anahtar kelimeler

Yenidoğan, ultrasonografi, tıp eğitimi

Keywords

Neonatal, ultrasonography, medical education

Geliş Tarihi/Received : 17.01 .2021

Kabul Tarihi/Accepted : 29.01.2021

DOI:10.4274/jcp.2021.0016

Yazışma Adresi (Sorumlu Yazar)/Address for Correspondence:

Burak Ceran, Sağlık Bilimleri Üniversitesi, Ankara Bilkent Şehir Hastanesi, Neonatoloji Kliniği, Ankara, Türkiye

\section{$\ddot{\mathbf{O} z}$}

Giriş: Türkiye' deki yenidoğan hekimlerinin klinik ultrasonografi (US) kullanımı, görüş ve deneyimleri hakkında bilgi bulunmamaktadır. Çalışmamızın amacı ülkemizdeki yenidoğan hekimlerinin klinik US kullanımı konusundaki, tutum, tercih, kullanım sıklığı ve bakış açılarının değerlendirilmesidir.

Gereç ve Yöntem: Çalışma Türkiye'deki yenidoğan hekimlerinin anket yoluyla elektronik ortamda 01 Şubat-1 Mart 2020 tarihleri arasında katılımı ile gerçekleştirildi. Katılımcıların yaş, cinsiyet, görev yapılan sağlık kurumu, yenidoğan yoğun bakımdaki deneyim süresi ve akademik unvan bilgileri kaydedildi. Ankete katılan katılımcılara, klinikte US kullanıp kullanmadı̆̆ı, kullanıyorsa hangi vücut bölgesi ve hangi girişim için kullandığı, bunun için eğitim alıp almadığı gibi sorular yöneltildi. Klinik US ile ilgili tutumları 5 noktalı Likert skalası ile değerlendirildi.

Bulgular: Çalışmaya 120 yenidoğan hekimi katıldı. Katılımcıların yaş ortalaması 40,38 $\pm 5,24$ y1l olarak bulundu. Katılımcıların kliniklerinde $\% 90(n=108)$ oranında US cihazı bulunurken katılımcılar arasında US yapma sıklığı \%69,1 (n=83) olarak tespit edildi. Klinikte US cihazı mevcudiyeti, kullanımı, klinik US eğitimine katılım, pediatrik radyoloji rotasyonunun yenidoğan yandal eğitim programında yer alması, kranial US, abdominal US ve santral ven kateterizasyonu için US kullanımı konusunda akademik ünvana göre cevaplarda gruplar arası fark bulunmadı $(\mathrm{p}>0,05)$. Akciğer US kullanımı yandal araştırma görevlisi grubunda $(\% 86,7)$ diğer akademik ünvanlara oranla anlamlı olarak daha yüksek oranda bulundu $(\mathrm{p}<0,05)$.

Sonuç: Çalışmamız alanındaki ilk ulusal çalışmadır; Ülkemizde kritik hasta grubu olan yenidoğanların tanısı, izlemi ve tedavisinde önemli yeri olan US'nin yenidoğan hekimleri tarafından yeterince etkin kullanılmadığı tespit edilmiştir.

\begin{abstract}
Introduction: There is no information about the clinical ultrasonography (US) use, opinion and experiences in neonatal physicians in Turkey. The aim of our study is to evaluate the attitudes, preferences, frequency of use and perspectives of neonatal physicians in our country regarding clinical use of US.

Materials and Methods: The study was conducted through a survey with the participation of neonatal physicians in Turkey with electronically between 1 February to 1 March 2020. The information about participants' age, gender, type of institution, experience period in neonatal intensive care and academic title were recorded. The participants were asked questions such as whether they use US in the clinic, if they are using, which part of body and for which
\end{abstract}


intervention, and whether they received training for this purpose. The attitudes about Clinical US were evaluated using a 5-point Likert scale.

Results: 120 neonatal physicians participated in the study. The average age of the participants was determined as $40.38 \pm 5.24$ years. While $90 \%(n=108)$ of the participants had US devices in their clinics, the use of frequency of US among the participants was found as $69.1 \%(n=83)$. There was no difference between groups in the answers according to academic title about US device availability in the clinic, use of, participation in clinical US training, pediatric radiology rotation in the neonatal fellow education program, use of US for cranial US, abdominal US and central vein catheterization ( $p>0,05)$. Lung US use was found at a significantly higher rate in the neonatology fellows group $(86.7 \%)$ compared to other academic titles $(\mathrm{p}<0.05)$.

Conclusions: The study is the first national study in its field. It has been determined that US, which has an important role in the diagnosis, monitoring and treatment of the critically ill group in Turkey, is not used effectively by neonatal physicians.

\section{Giriş}

Ultrasonografi (US) kullanımı, hızlı, erişilebilir ve hasta başı uygulanabilir olması, ön hazırlığa gereksinim duyulmaması, radyasyon riskinin olmaması gibi uygulamada kolaylaştırıcı sebeplerden ve etkinliğinden dolayı günlük pratiğe girmiştir (1). Hasta başında yapılan hedefe yönelik US (HYUS) son zamanlarda tanımlanmıştır. Klinisyen tarafından hasta bazında ve hedefe yönelik soruyu cevaplamak amaciyla yapilır ve yorumlanabilir (2).

Son yirmi yılda, tüm dünyada klinik tıbbın birçok alanında HYUS kullanımı önemli ölçüde artmıştır (3). Amerika Birleşik Devletleri'nde HYUS eğitimi için birçok uzmanlık dalının (acil tıp, anesteziyoloji, kadın doğum gibi) eğitim müfredatı yapılandırılmıştır (4). Avustralya ve Yeni Zelanda gibi ülkelerde resmi bir akreditasyon programı çerçevesinde neonatoloji hekimleri için eğitim ve sertifika programı düzenlenmektedir (5). Resmi bir eğitim programı veya sertifikası mevcut olmamasına rağmen Avrupa'daki yenidoğan hekimleri arasında HYUS kullanımı giderek yaygınlaşmaktadır (6).

Son yıllarda yoğun bakım hekimleri tarafından HYUS kullanımının giderek artmasına rağmen yenidoğan hekimlerinin bu konudaki deneyimleri sınırlıdır. Ayrıca, Türkiye'de radyoloji rotasyonu ile, US eğitimi birçok dahili ve cerrahi branşın uzmanlık eğitim müfredatında yer alırken, yenidoğan yan dal uzmanlık eğitiminde bulunmamaktadır (7). $\mathrm{Bu}$ çalışmada, Türkiye'de görev yapan yenidoğan hekimlerinin klinik US kullanımı konusundaki, tutum, tercih, kullanım sıklığı ve bakış açılarının değerlendirilmesi amaçlanmıştır.

\section{Gereç ve Yöntem}

$\mathrm{Bu}$ çalışmada kullanılan, anket elektronik ortamda 01 Şubat-1 Mart 2020 tarihleri arasında gerçekleştirildi. Çalışma öncesinde Ankara Bilkent Şehir Hastanesi bilimsel etik komiteden etik kurul onamı (Karar no: E1/276/2020) alındı. Türkiye' de aktif olarak görev yapan yenidoğan hekimleri ile yüz yüze görüşülerek ya da mobil telefonlara "Google Forms" aracılığılla hazırlanan "Yenidoğan Hekimlerinin Klinik Ultrasonografi Kullanımı ve Bakışının Değerlendirilmesi" anketinin yer aldığı formun sayfa uzantısı gönderilerek formun doldurulması sağlandı. Yurt dişında çalışan ve aktif görev yapmayan hekimler çalışma dışı bırakıldı. Katılımcılara anketin giriş kısmında anketin amacı ve niteliği ile ilgili bilgilendirme yapıldı. Bilgilendirilmiş onamın ardından katılımcılardan isim, soy isim, çalışılan kurumun adı gibi özel bilgiler alınmadan anket formunu doldurmaları istendi. Soru seçeneklerinde tarafsızlık ve katılımcıların yanıtlarının yönlendirilmemesi ilkesine uygun davranıldı. Anketin tamamlanması için herhangi bir zaman kısıtlaması yapılmad1.

İlk beş soru demografik verileri değerlendirmek amacıyla yaş, cinsiyet, görev yapılan sağlık kurumunun niteliği, yenidoğan yoğun bakım ünitesindeki (YDYBÜ) deneyim süresi ve akademik ünvan bilgilerine yönelik soruları içermekteydi. 8 soru ise yenidoğan hekimlerinin US'nin kliniğe katkısıyla ilgili düşüncelerini öğrenmek için 5'li Likert tipinde derecelendirilen 1 ölçek taslağı olan Likert 5 seçenekli skorlama sisteminden (1=kesinlikle katiliyorum, 2=katılıyorum, 3=fikrim yok, 4=katılmıyorum, 5=kesinlikle katılmıyorum) oluşmaktaydı (8). Uygulanan anket ile ilgili sorular Tablo 1'de sunulmuştur.

\section{Ístatistiksel Analiz}

Anket verileri bilgisayar ortamında SPSS 20'ye (Statistical Package for Social Sciences) 
(IBM, Armonk,N.Y.,USA) yüklendi ve analiz karşılaştırmak için ANOVA yöntemi kullanıldı edildi. Değişkenlerin normal dağılıma uygunluğu ve anlamlı farklılığın belirlendiği yerlerde farkın görsel (histogram ve olasılık grafikleri) ve analitik kimden kaynaklandığını belirlemek için post-hoc kiyöntemler (Kolmogorov-Smirnov/Shapiro-Wilk Testi) kullanılarak incelendi. Kategorik değişkenlerin değerlendirmesinde Pearson Chi-Square test ve Fisher's Exact test uygulandi. İkiden fazla grubu kare kullanıldı. Devamlı değişkenler normal dağılım gösteren verilerde ortalama \pm standart sapma, kategorik değişkenler için sıklık olarak ifade edildi. İstatistiksel anlamlılık düzeyi $\mathrm{p}<0,05$ olarak kabul edildi.

Tablo 1. Yenidoğan hekimlerinin klinik ultrasonografi kullanımına bakışının değerlendirilmesi anket soruları

\begin{tabular}{ll}
\hline Sıra & Sorular \\
\hline 1. & Cinsiyetinizi belirtiniz? \\
2. & Yaşınız? \\
3. & Hangi Kurumda görev yapmaktasınız? \\
4. & Çalıştı̆̆ınız kurumdaki akademik ünvanınızı belirtiniz? \\
5. & Yenidoğan yoğun bakımdaki çalışma süreniz? \\
6. & Kliniğinize ait bir Ultrasonografi cihazı var mı? \\
7. & Ultrasonografi cihazını kullanıyor musunuz? \\
8. & Ultrasonografi cihazını kaç yıldır kullanıyorsunuz? \\
9. & Neonatoloji klinik pratiğinde Ultrasonografinin katkısının olduğunu düşünüyor musunuz? \\
10. & Klinik Ultrasonografi eğitimi için kursa katıldınız mı? \\
11. & Ultrasonografi eğitimi için yapılan kursların faydalı olduğunu düşünüyor
\end{tabular}

12. Neonatoloji yandal asistanlık eğitimi süresince klinik ultrasonografi kullanımının yeterli olduğunu düşünüyor musunuz?

13. Pediatrik radyoloji rotasyonu neonatoloji yandal eğitim programında yer almalı mıdır?

14. Yandal Araştırma Görevlisi iseniz hangi kurumda uzmanlık eğitimi almaktasınız, bulunduğunuz kurumda eğitimcileriniz tarafından Ultrasonografi eğitimi veriliyormu?

15. Klinik pratiğinizde hangi alanlarda Ultrasonografik görüntülemeler yapıyorsunuz?

16. Kranial Ultrasonografik görüntüleme ve değerlendirme yapıyor musunuz?

17. Kranial Ultrasonografik değerlendirmeniz sırasında hangi ölçümleri yapiyorsunuz?

18. Kranial Ultrasonografik görüntüleme ve değerlendirme yapıyor olmanın yenidoğan hekimlerinin klinik pratiğine katkı sağladığını düşünüyor musunuz?

19. Akciğer Ultrasonografik görüntüleme ve değerlendirme yapıyor musunuz?

20. Akciğer Ultrasonografik değerlendirme ve görüntülemesini hangi amaçlar için yapıyorsunuz?

21. Akciğer Ultrasonografik görüntüleme ve değerlendirmesi yapıyor olmanın yenidoğan hekimlerinin klinik pratiğine katkı sağladığını düşünüyor musunuz?

22. Abdominal Ultrasonografik görüntüleme ve değerlendirme yapıyor musunuz?

23. Abdominal Ultrasonografik değerlendirme ve görüntülemesini hangi amaçlar için yapıyorsunuz?

24. Abdominal Ultrasonografik görüntüleme ve değerlendirme yapıyor olmanın yenidoğan hekimlerinin klinik pratiğine katkı sağladığını düşünüyor musunuz?

25. Santral ven(Juguler/Subklaviyan/Femoral) kateterizasyonu yapıyorsanız hangi sıklıkla yapıyorsunuz?

26. Santral ven kateterizasyonunda hangi girişimlerde Ultrasonografi kullaniyorsunuz?

27.

Santral ven kataterizasyonun da ultrasonografik görüntüleme ve değerlendirme yapıyor olmanın yenidoğan hekimlerinin klinik pratiğine katkı sağladığını düşünüyor musunuz? 


\section{Bulgular}

Çalışmaya toplam 120 yenidoğan hekimi katıldı. Katılımcıların \%90'1 (n=108) kliniklerinde US cihazı bulunduğunu belirtirken, katılımcılar arasında US yapma sıklığı \%69,1 (n=83) olarak tespit edilmiştir. Katılımcıların yaşları 29 ile 57 yıl arasında değişmekte olup yaş ortalaması 40,38 $\pm 5,24$ yıl olarak bulundu. Ultrasonografi kullanan katılımcıların yaş ortalaması $40,46 \pm 5,20$ yıl, kullanmayanların yaş ortalaması ise 40,22 $\pm 5,38$ y1l olarak tespit edildi $(\mathrm{p}=0,817)$. Katılımcıların YDYBÜ'deki çalışma süreleri 1 ile 22 yıl arasında değişmekte olup ortalama çalışma süresi $8,10 \pm 4,77$ y1l olarak tespit edildi. Ultrasonografi kullanan katılımcıların YDYBÜ'de çalışma süresi $8,34 \pm 4,78$ y1l olarak bulunurken US kullanmayan

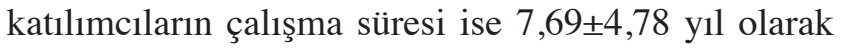
tespit edildi $(\mathrm{p}=0,502)$. Katılımcıların \%53,3’ü $(\mathrm{n}=64)$ kadın cinsiyetti. Erkek katılımcıların YDYBÜ'de çalışma süreleri $(9,05 \pm 4,98$ yıl $)$ kadın katılımcıların çalışma sürelerinden $(7,27 \pm 4,45$ y1l $)$ anlamlı olarak daha uzun tespit edildi $(\mathrm{p}=0,042)$. Katılımcilarının $\% 38,3$ 'ü (n=46) üniversite hastanesinde, \%49,2'si $(n=59)$ eğitim araştırma hastanesinde, \%7,5’i (n=9) devlet hastanesinde, \%5'i $(\mathrm{n}=6)$ özel hastanede görev yapmaktaydı. Katılımcıların büyük çoğunluğu \%43,3 $(\mathrm{n}=52)$ oran ile uzman doktor iken bu oran1 \%30,8 $(\mathrm{n}=37)$ ile doçent doktor ünvanlı katılımcılar takip etmektedir. Ek olarak, \%7,5 (n=9) oranında profesör doktor ve \%18,3 $(\mathrm{n}=22)$ oranında yan dal araştırma görevlisi çalışmaya katılmıştır. Katılımcıların cinsiyet, akademik unvan, çalıştı $\breve{g}_{1}$ kurum ve YDYBÜ deneyimine ait sonuçlar Tablo 2'de sunulmuştur.

Klinikte US cihazı mevcudiyeti, kullanımı, klinik US eğitimi için kursa katılım ve pediatrik radyoloji rotasyonu yenidoğan yan dal eğitim programında yer almalı mi? sorusuna verilen cevaplarda akademik ünvana göre gruplar arasında fark bulunmadı $(\mathrm{p}>0,05)$ (Tablo 3). Kraniyal US, abdominal US ve santral ven kateterizasyon için US kullanımı açısından akademik ünvanlar arası fark bulunmadı $(\mathrm{p}>0,05)$. Ancak akciğer US kullanımı yan dal araştırma görevlilerinde $(\% 86,7)$ diğer akademik ünvanlara göre anlamlı olarak daha yüksek tespit edildi $(\mathrm{p}<0,05)$ (Tablo 4). Kraniyal US, akciğer US, abdominal US ve santral ven kateterizasyon için US kullanımı açısından çalışılan kurumlara göre gruplar arasında istatistiksel fark bulunmadı $(\mathrm{p}>0,05)$ (Tablo 5).

Yenidoğan yan dal asistanlık eğitimi sürecinde klinik US kullanımını kesinlikle yeterli ve yeterli bulanlarda en yüksek oran \%33,3 ile profesör doktorlarda iken yetersiz ve kesinlikle yetersiz bulanlarda en yüksek oran \%78,4 ile doçent doktorlardadır. Üniversitede görev yapan yan dal araştırma görevlilerinde klinik US eğitimi için kursa katılma oranı \%35,7 (n=5) iken eğitim araştırma hastanelerinde bu oran \%12,5 $(n=1)$ olarak tespit edildi. Klinik US eğitimi kursuna katılan katılımcı oranı \%47,5 (57 kişi) olarak tespit edildi. Ultrasonografi cihazını kullanan katılımcıların \%59'u (49 kişi) daha önce klinik US eğitim kursuna

Tablo 2. Demografik özellikler

\begin{tabular}{lc}
\hline Katılımcı bilgileri & $\mathrm{n}=120$ \\
\hline Cinsiyet & $64(\% 53,3)$ \\
Kadın, n (\%) & $9(\% 7,5)$ \\
Akademik Ünvan & $37(\% 30,8)$ \\
Profesör Doktor, n (\%) & $52(\% 43,3)$ \\
Doçent Doktor, n (\%) & $22(\% 18,3)$ \\
Uzman Doktor, n (\%) & \\
Yandal Araştırma Görevlisi, n (\%) & $46(\% 38,3)$ \\
Çalıştı̆̆ı Kurum & $59(\% 49,2)$ \\
Üniversite Hastanesi, n (\%) & $9(\% 7,5)$ \\
Eğitim Araştırma Hastanesi, n (\%) & $6(\% 5)$ \\
Devlet Hastanesi, n (\%) & \\
Özel Hastane, n (\%) & $36(\% 30)$ \\
Yenidoğan Yoğun Bakım Deneyimi & $49(\% 40,8)$ \\
$<=5$ yıl, $\mathrm{n} \%)$ & $35(\% 29,2)$ \\
5-10 yıl, n (\%) & \\
$>10$ yıl, n (\%) & \\
\hline
\end{tabular}


katıldı ̆̆ını belirtmiştir. Ultrasonografi cihazını kullanmayan katılımcılarda bu oran \%21,6 (8 kişi) olarak tespit edildi. Klinik US eğitimi kursu alan katılımcılarda US kullanma oranı \%86 (49 kişi) iken kursa katılmayan katılımcılarda bu oran \%54 (34 kişi) olarak tespit edildi. Klinik US eğitimi alma durumu ile US kullanım oranının arttığ tespit edildi $(\mathrm{p}<0,05)$.

Ultrasonografi kullanan katılımciların \%91,5'i $(\mathrm{n}=76)$ klinik pratiklerinde US ile kraniyal görüntüleme yaptığını belirtirken, \%51,8’i $(n=43)$ akciğer görüntülemesi, \%33,7'si $(n=28)$ abdominal görüntüleme ve $\% 31,3$ 'ü $(\mathrm{n}=26)$ ise vasküler girişim için yaptığını belirtmiştir. Kraniyal görüntüleme $\% 96,0$ gibi $(n=73)$ en yüksek oranla intrakraniyal kanama tanı ve takibini için yapıldı $\breve{g}_{1}$ tespit edildi. Akciğer US değerlendirmesi yapan hekimlerin \%87,5'i (n=35) plevral effüzyonu, \%82,5'i $(\mathrm{n}=33)$ respiratuvar distres sendromunu ve \%77,5'i $(n=31)$ ise pnömotoraks değerlendirmesi için US kullandığ 1 belirlenmiştir. Abdominal US'nin \%57,1'i $(n=16)$

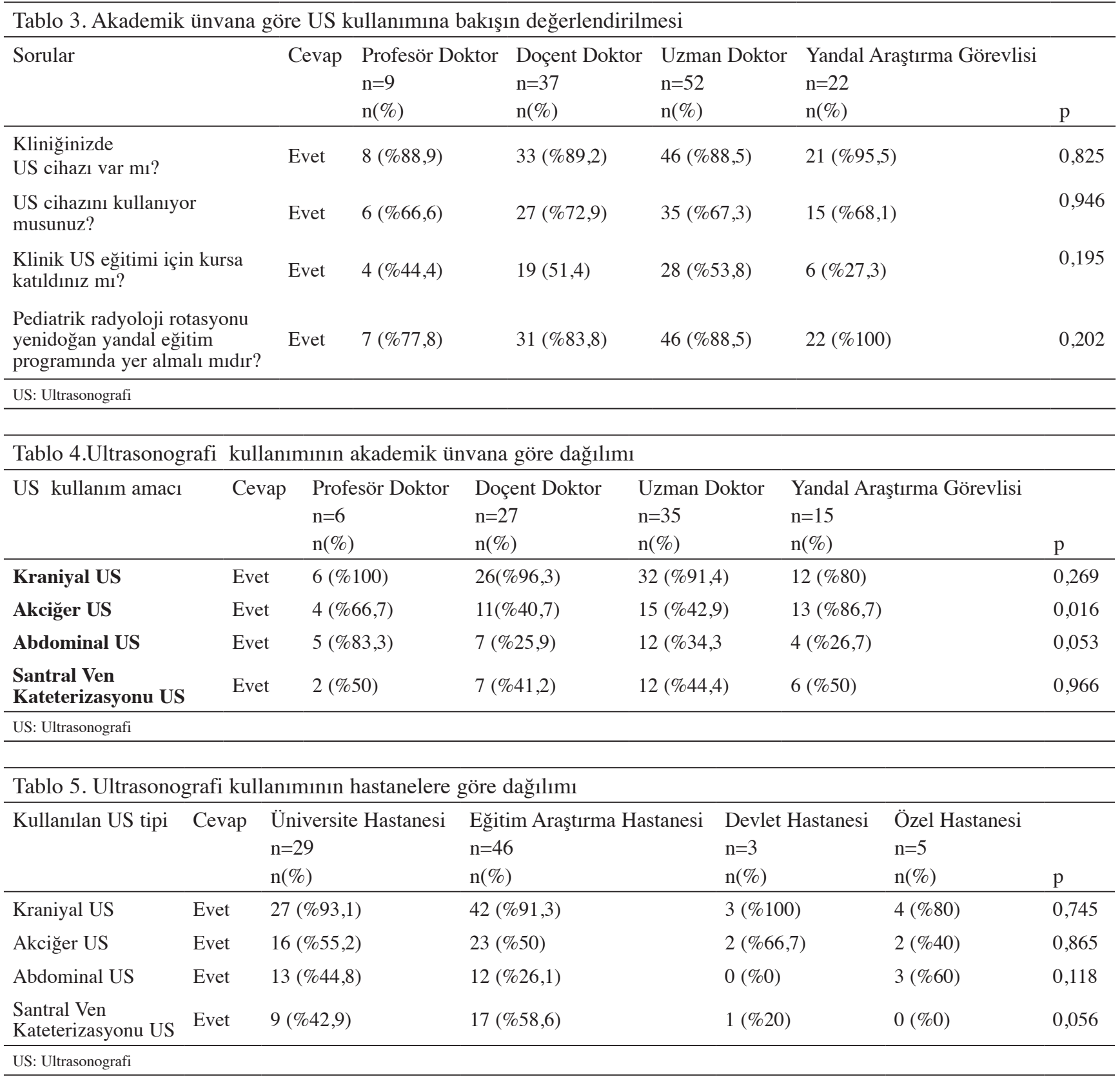


abdominal acil durumlarda, \%53,5'i $(\mathrm{n}=15)$ umblikal venöz/arter kateter yerleşiminin değerlendirilmesinde, \%39,2'si (n=11) solid organ değerlendirmesinde, $\% 35,7$ 'si $(\mathrm{n}=10)$ nekrotizan enterekolit (NEK) tan1 ve takibinde, \%14,2'si $(\mathrm{n}=4)$ ise intestinal motilite değerlendirmesinde kullandığı tespit edildi.

Santral ven kateterizasyon yapan katılımciların

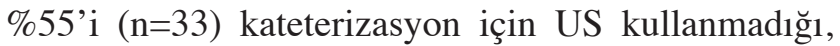
\%45'i (n=27) ise US kullandığ 1 tespit edildi. Santral ven kateterizasyon yapanların \%11,66's1 $(\mathrm{n}=7)$ femoral ven kateterizasyonu sirasinda, \%36,6's1 $(n=22)$ juguler ven kateterizasyonu sirasinda ve \%13,3'ü $(\mathrm{n}=8)$ subklavyen ven kateterizasyonu sirasinda US kullandığ belirlenmiş̧tir.

\section{Tartışma}

$\mathrm{Bu}$ çalışma, ülkemizdeki yenidoğan hekimleri üzerinde US kullanım oranlarını, tutum ve görüşlerini ulusal düzeyde ilk olarak araştıran çalışmadır. Bu çalışmanın sonuçları, yenidoğan hekimlerinin klinikte US kullanımı, akademik ünvana ve çalışılan kuruma göre US'nin klinikte yeri ve US'ye bakış açısı ile ilgili önemli bilgiler vermektedir. Birçok klinikte US cihazının var olduğu, yaklaşık 3 yenidoğan hekiminden 2'sinin US kullandığı, kurs katılım oranlarının akademik ünvanla arttığı ve US eğitimi alınmasını düşünenlerin oranının yüksek olduğu saptanmıştır. Ayrıca US kullanım alanları açısından akademik ünvanlar arasında fark bulunmaz iken, özellikle son dönemde kullanımı artan akciğer US'sinin yan dal araştırma görevlileri tarafından daha yüksek oranda kullanıldığ 1 tespit edilmiştir.

Amerika Birleşik Devletleri'nde eğitim alan yenidoğan hekimlerine US eğitimi verilmemektedir. Ancak hedefe yönelik ekokardiyografi eğitimi verilir ve bu eğitim için kılavuzlar yayınlanmıştır $(9,10)$. Birçok uzman US eğitimlerinin geliştirilmesine, standardize edilmesine ve kalite standartlarının belirlenmesine ihtiyaç olduğunu vurgulamaktadır (11). Tipta uzmanlık kurulu verilerine göre çocuk acil, çocuk nörolojisi, enfeksiyon hastalıkları ve klinik mikrobiyoloji, fiziksel tıp ve rehabilitasyon, gastroenteroloji, göğüs hastalıkları, iç hastalıkları, nefroloji gibi ana dal ve yan dal eğitim programlarında radyoloji rotasyonu yer almaktadır (7). Ülkemizde birçok ana dal ve yan dal eğitiminde radyoloji rotasyonu olmasına rağmen yenidoğan yan dal eğitim programında pediatrik radyoloji rotasyonu yer almamaktadır.
Sonuçlarımıza göre katılımcıların $\% 88,3$ 'ü pediatrik radyoloji rotasyonunun yenidoğan yan dal eğitim programına dahil edilmesi gerektiğini düşünmektedir. Yan dal araştırma görevlisi katılımcıların tamamı US eğitiminin, eğitim programında yer alması gerektiği konusunda görüş bildirirken profesör doktorlarda bu oran azalmaktadır. Ülkemizde standart bir US eğitim programı mevcut değildir. Ancak, üniversite hastanelerinde görev yapan yan dal araştırma görevlilerinde eğitimcilerinden US eğitimi alma oranı eğitim araştırmadaki yan dal araştırma görevlilerinden istatiksel olarak anlamlı yüksek tespit edilmiştir.

Ülkemizde Türk Neonatoloji Derneği (TND) tarafından aralıklı olarak ülkemizin farklı bölgelerinde US kursları düzenlenmektedir. Çalışmamızda akademik unvan artışı ile klinik US eğitimi için kursa katılım oranının artığ 1 ve kurs katılım oranın en düşük yan dal araştırma görevlilerinde $\% 27,3$ olduğu bulundu. $\mathrm{Bu}$ durum kursa katılım için yeterli kontenjana sahip olunamamasından, yan dal araştırma görevlilerinin yoğun çalışma ve nöbet temposu dolayısıyla vakit bulamamasından ve görevdeki hizmet süresinin kısa olmasından kaynaklanıyor olabilir. Kursa katılanların ise büyük çoğunluğu kursların kesinlikle faydalı ya da faydalı olduğu şeklinde görüş bildirmektedir. Dolayısıyla kursların sayısının arttırılması ve yan dal araştırma görevlilerine yönelik ek kursların düzenlenmesi düşünülebilir.

Kraniyal US izleminin yenidoğan uzmanları tarafından yapılması dünyada giderek yaygınlaşan bir uygulamadır. Kraniyal US ile görüntüleme bazı ülkelerde yenidoğan hekimleri tarafından yıllardır uygulanmaktadır (9). Sonuçlarımıza göre US kullanan katılımcıların büyük oranda intrakraniyal kanama tanı ve takibini için kraniyal US yaptıkları belirlenmiştir. Özellikle intrakraniyal kanamanın sık görüldüğü prematüre hastalarda s1k aralıklarla kraniyal US takibi yapılması bu yüksek oranı açıklamaktadır.

Akciğer US, YDYBÜ'de yatak başı kolay uygulanması, tanısal açıdan güvenilir bilgi vermesi, akciğer direkt grafisine kıyasla radyasyon hasarı oluşturmaması ve düşük maliyetli olmasından dolayı avantajlıdır (12). Bazı YDYBÜ'lerde akciğer US direkt grafisinin yerini almış ve yenidoğanın akciğer hastalıklarının tanı ve ayırıcı tanısı için kullanılan ilk basamak yaklaşım olmuştur (13). Çalışmaya katılan yenidoğan hekimlerinin yaklaşık yarısı akciğer US görüntüleme yapıyor olması ülkemizde bu konuda 
yeterli eğitim ve eğilimin olmadığının göstergesidir. Ayrıca ankete katılanlar içinde akciğer US kullanım oranının en yüksek yan dal araştırma görevlilerinde olduğu dikkati çekmektedir. Dünya genelinde akciğer US standardizasyonu için kılavuzlar hazırlanmıştır. Ülkemizde bu tip bir kılavuz bulunmamaktadır (13). Yenidoğan hekimlerinin sik karşılaştığı akciğer hastalıklarına US yaklaşımı ile ilgili ülkemizde daha geniş çaplı eğitimlere ihtiyaç olduğu düşüncesindeyiz.

Katılımcilar abdomen US kullanırken sıklık sırasına göre kullanım sebepleri acil durumlar, umbilikal venöz/arter kateter yerleşiminin, solid organ değerlendirmesi, NEK tanı ve takibi ile intestinal motilite değerlendirmesi olarak beyan etmiştir. Abdominal US umblikal venöz kateterin yerini doğrulamak için radyografiye kıyasla oldukça iyi bir alternatiftir $(14,15)$. Abdominal direkt grafiler, özellikle preterm bebeklerde NEK tanısinda US'ye göre oldukça düşük özgüllük ve duyarlılığa sahiptir. Çoklu radyografiler genellikle teşhis veya NEK'li bebeklerin izleminde kullanılır. Abdominal US ise radyografinin yetersiz kaldığ 1 durumlarda yardımcı olur ve ayrica, NEK'in erken tespit edebilmesine de olanak sağlar (16). Son yayınlanan TND, nekrotizan enterokolit tan1, tedavi ve korunma rehberi 2021'de NEK'in tanısında abdominal US'nin kullanımının direkt radyografiye üstünlüğü vurgulanmaktadır (17). Kraniyal US'de göreceli yükssek kullanım oranı varken, abdominal US'deki düşük kullanım oranları radyoloji hekimlerine ulaşımın kolay olmasına, deneyimin az olması ve yenidoğan hekimlerinin yasal çekincelerinden kaynaklanıyor olabilir.

Yenidoğan bebeklerde vasküler erişim, YDYBÜ'de önemli ve en sık kullanılan invaziv bir girişimdir (18). Santral venöz kateter yerleştirilmesi esnasında US kullanımı ile olası komplikasyonlar azalmaktadır (18-20). Matava ve ark.'nın yaptığı çalışmada, katılımcıların \%54'ünün santral kateterizasyonda rutin US kullandıklarını ve en sık juguler venöz kateterizasyonda tercih ettiklerini belirtmişlerdir (21). Santral ven kateterizasyonu yapan katılımcılarımızın \%45'i kateterizasyon için US kullandığını belirtmiştir ve bu oran erişkin literatür verilerine kıyasla daha düşük bulunmuştur. Buna rağmen çalışmamıza katılan katılımcılar literatür ile benzer şekilde en sık juguler venöz kateterizasyon girişimi esnasında US kullanımını tercih ettikleri belirlenmiştir $(20,21)$.
Çalışmamızın bazı kısıtlılıkları vardır. Ülke genelinde TND'ye yaklaşık 400 hekim kayıtlıdır. Kayıtlı olanlar en az yenidoğan uzmanı düzeyindedir. Yenidoğan yan dal eğitimi gören hekimler kayıtlı değildir. Dolayısıyla eğitim alan hekimlerde dahil olmak üzere ülke genelinde yenidoğan hekim sayısı net olarak bilinmemektedir. Buna bilgiye göre ülke genelinde tüm yenidoğan hekimlerinde ankete katılım oranları kesin olarak belli değildir. Ayrıca, çalışmanın metodu gereği hekimlerin çalıştığı kurum bilgileri anket sorusunda yer almadığı için ülke genelinde toplam kaç merkezin katıldığının verisine sahip değiliz. Bu açıdan çalışmamız kısıtlılığa sahiptir.

$\mathrm{Bu}$ araştırma, ülkemizdeki klinik US eğitimi ile ilgili eksikliklerin belirlenmesi açısından yapılan ilk araştırmadır. Türkiye'de görev yapan yenidoğan hekimlerinin klinik US kullanımı konusundaki, tutum, tercih, kullanım sıklığı ve bakış açılarını değerlendirmesi üzerine yaptığımız bu anket çalışması öncelikli olarak US konusunda klinisyenlerin kullanım oranı ve tecrübesinin istenilenden daha düşük olduğunu göstermiştir. Ultrasonografi eğitiminin yenidoğan yan dal eğitimi sırasında ya da uzmanlık eğitimini tamamladıktan kısa süre sonra erken dönemde alınarak US değerlendirme yapabilme becerisinin kazandırılması hem klinisyene hasta yönetiminde kolaylık sağlarken hem de hastanın sağ kalımında iyileşmeye yardımcı olabilir. Hedefe yönelik US yenidoğan hekimleri için hasta takibinde tamamlayıcı bir uygulama olmalıdır. Ancak, kesinlikle radyolog değerlendirmesine alternatif olarak düşünülmemelidir. Sonuç olarak, standardize edilmiş bir US eğitiminin yan dal eğitim programına dahil edilmesi ve halen görev yapmakta olan yenidoğan hekimleri için standardize eğitimlerin yaygınlaştırılarak düzenlenmesinin yararlı olacağ 1 kanaatindeyiz.

\section{Etik}

Etik Kurul Onayı: Çalışma öncesinde Ankara Bilkent Şehir Hastanesi bilimsel etik komiteden etik kurul onamı (Karar no: E1/276/2020) alındı.

Çıkar Çatışması: Yazarlar tarafından çıkar çatışması bildirilmemiştir.

Finansal Destek: Yazarlar tarafından finansal destek almadıkları bildirilmiştir. 


\section{Kaynaklar}

1. Coker BJ, Zimmerman JM. Why Anesthesiologists Must Incorporate Focused Cardiac Ultrasonography Into Daily Practice. Anesth Analg 2017;124:761-5.

2. Moore CL, Copel JA. Point-of-care ultrasonography. N Engl J Med 2011;364:749-57.

3. Gillman LM, Kirkpatrick AW. Portable bedside ultrasound: the visual stethoscope of the 21st century. Scand J Trauma Resusc Emerg Med 2012;20:18.

4. Deshpande R, Montealegre-Gallegos M, Matyal R, Belani $\mathrm{K}$, Chawla N. Training the anesthesiologist in point-of-care ultrasound. Int Anesthesiol Clin 2016;54:71-93.

5. Singh Y, Gupta S, Groves AM, Gandhi A, Thomson J, Qureshi $\mathrm{S}$, et al. Expert consensus statement 'Neonatologist-performed Echocardiography (NoPE)'-training and accreditation in UK. Eur J Pediatr 2016;175:281-7.

6. Roehr CC, Te Pas AB, Dold SK, Breindahl M, Blennow M, Rüdiger $\mathrm{M}$, et al. Investigating the European perspective of neonatal point-of-care echocardiography in the neonatal intensive care unit-A pilot study. Eur J Pediatr 2013;172:907-911.

7. Tipta Uzmanlık Kurulu. Uzmanlık Eğitimi Rotasyonları, 82 sayılı Karar Eki, 2010, s: Ek sayfa 10-17.

8. Likert R. A technique for the measurement of attitudes. Archives of Psychology 1932;22:5-55.

9. Evans N, Gournay V, Cabanas F, Kluckow M, Leone T, Groves A, et al. Point-of-care ultrasound in the neonatal intensive care unit: international perspectives. Semin Fetal Neonatal Med 2011;16:61-68

10. Mertens L, Seri I, Marek J, Arlettaz R, Barker P, McNamara P, et al. Targeted neonatal echocardiography in the neonatal intensive care unit: practice guidelines and recommendations for training. Eur J Echocardiogr 2011;12:715-736.

11. Finan E, Sehgal A, Khuffash AE, McNamara PJ. Targeted neonatal echocardiography services: need for standardized training and quality assurance. J Ultrasound Med 2014;33:18331841.

12. Cattarossi L, Copetti R, Poskurica B. Radiation exposure early in life can be reduced by lung ultrasound. Chest 2011;139:730-1.
13. Liu J, Copetti R, Sorantin E, Lovrenski J, Rodriguez-Fanjul J, Kurepa D, et al. Protocol and guidelines for point-of-care lung ultrasound in diagnosing neonatal pulmonary diseases based on international expert consensus. J Vis Exp 2019;145.

14. Pulickal AS, Charlagorla PK, Tume SC, Chhabra M, Narula P, Nadroo AM. Superiority of targeted neonatal echocardiography for umbilical venous catheter tip localization: accuracy of a clinician performance model. J Perinatol 2013;33:950-953.

15. Michel F, Brevaut-Malaty V, Pasquali R, Thomachot L, Vialet R, Hassid S, et al. Comparison of ultrasound and X-ray in determining the position of umbilical venous catheters. Resuscitation 2012;83:705-709.

16. Miller LE, Stoller JZ, Fraga MV. Point-of-care ultrasound in the neonatal ICU. Curr Opin Pediatr 2020;32:216-227.

17. Ergenekon E, Tayman C, Özkan H. Nekrotizan enterokolit tanı, tedavi ve korunma rehberi-2021; 1-48.

18. Bodenham Chair A, Babu S, Bennett J, Binks R, Fee P, Fox B, et al. Association of Anaesthetists of Great Britain and Ireland: Safe vascular access 2016. Anaesthesia 2016;71:573-85.

19. McGee DC, Gould MK. Preventing complications of central venous catheterization. N Engl J Med 2003;348:1123-33.

20. Serafimidis K, Sakorafas GH, Konstantoudakis G, Petropoulou K, Giannopoulos GP, Danias N, et al. Ultrasonography-guided catheterization of the internal jugular vein in oncologic patients; comparison with the classical anatomic landmark technique: a prospective study. Int J Surg 2009; 7:526-8.

21. Matava C, Hayes J. A survey of ultrasound use by aca $\neg$ demic and community anesthesiologists in Ontario. Can J Anaesth 2011;58:929-35. 